\title{
A Cross-Sectional Analysis of the Prevalence and Determinants of Mental Distress Among Ethiopian Returnees
}

\author{
Derebe Madoro \\ Department of Psychiatry, Dilla \\ University's College of Medicine and \\ Health Sciences, Dilla, Ethiopia
}

Background: Returning internally displaced persons (IDPs) to their homes can be a difficult and traumatic experience, particularly after a long period of displacement. Furthermore, traumatic experiences encountered during displacement during the flight process may be replayed in the minds of IDP returnees when they return to their original locations, raising the risk of re-traumatization. This could have a detrimental impact on the mental health of returning IDPs. Despite this, the mental health of returnee IDPs in Ethiopia has received less consideration. As a result, the aim of this study was to determine the prevalence and determinants of mental distress among Ethiopian returnees.

Method and Participants: A community-based cross-sectional study with 623 participants was conducted from January 1 to 30, 2021, using a systematic sampling technique. The Kessler psychological distress scale was used to assess mental distress (K-10). Bivariable and multivariable binary logistic regression is used to investigate the relationship between variables. Statistical significance was described as a P-value of less than 0.05 with a $95 \%$ confidence interval.

Results: The total number of people interviewed was 623 , with a $100 \%$ response rate. With a $95 \%$ confidence interval of 47 to 51.9 , the prevalence of psychological distress was $49.4 \%$. Unemployment ( $\mathrm{AOR}=2.1,95 \% \mathrm{CI} 1.38$ to 3.40 ), inadequate social support ( $\mathrm{AOR}=1.92$, 95\% CI 1.53 to 2.56), having little knowledge of post-returnee life (AOR=2.17, 95\% CI 1.23 to 3.37), and the number of traumatic events ( $\mathrm{AOR}=1.92,95 \% \mathrm{CI} 1.53$ to 2.56 ) were all found to be significant in the multivariate logistic regression.

Conclusion: Returnee IDPs have a high prevalence of psychological distress, according to this report. It is suggested that knowledge of how to adapt to a new life after returning to the original land be given, as well as consistent psychosocial help.

Keywords: mental distress, returnee, displacement, Ethiopia
Correspondence: Derebe Madoro Email derebemd@gmail.co

\section{Introduction}

Internal and external displacement is on the rise across the world, owing to conflicts and natural disasters, as well as socioeconomic factors. ${ }^{1,2}$ According to the Internal Displacement Monitoring Centre (IDMC), about 30.6 million people are internally displaced around the world. ${ }^{3}$ The majority of them live in low-income countries that are prone to internal conflict and abuse. ${ }^{3}$ In 2016, almost 12.6 million people were displaced in Africa as a result of violence. ${ }^{4}$ Ethiopia had 2.9 million internally displaced people in $2018 .^{3}$

Because ethnic conflicts along the borders of Gede'o (SNNPR) and West Guji (Oromo region) zones led to large-scale displacement, the violence was started in 
April 2018, followed by the Ethiopian government began repatriating internally displaced people in May 2019. ${ }^{3}$ Nearly a million IDPs fled out of the conflict zone to thirteen peaceful areas within the two regions. A fouryear recovery project (2019-2022) is underway in both regions to support heavily affected IDPs returnees and communities. Recently, there have been no difficulties regarding racial minorities in going back because the conflict was resolved peacefully between the two ethnic groups before returning to their original home. When the displaced people fled, livestock and other properties were said to have been lost, and at least 9000 houses were said to have been entirely or partially destroyed during the fighting. ${ }^{5}$ People who have been displaced are more likely to be subjected to various types of trauma, abuse, and accidents, making them more vulnerable to mental distress. $^{4}$

According to returnees of externally displaced people, a study from a German report, $37 \%$ of displaced people were diagnosed with mental distress at the time of their arrival. ${ }^{9}$ Those who returned to Kosovo after eighteen months were diagnosed with mental distress $52.5 \%$, and those who were resettled in Sweden were $85.3 \%$. In a related report, researchers discovered a $25 \%$ rate of mental illness, such as mental distress, among returnees ${ }^{10}$ similarly, in twenty-one of the returnees, $48.3 \%$ had at least one psychiatric illness. ${ }^{9}$

Returnees from the Middle East recorded 11.7\% mild, $8.2 \%$ moderate, and $3 \%$ extreme mental distress in Ethiopia, ${ }^{11}$ while mental distress was reported $27.6 \%$ in South Africa and $29.2 \%$ in the Middle East. ${ }^{12}$ According to various reports, mental illness and mental distress are present in $3-87 \%$ of returnees. ${ }^{10,12-15}$

Evidence suggests that among crisis-affected communities, the prevalence of mental distress rises from $10 \%$ to $15-20 \%$, whereas serious mental disorders such as psychosis or crippling depression and anxiety rise from 1-2\% to $3-4 \% .{ }^{16}$ Mental distress rates of $15-55 \%$, depending on the research, have been found in returnee IDPs. ${ }^{17}$

The impact of relocation or return migration following forced internal displacement on mental health is poorly understood. ${ }^{1}$ The displaced population either returns to their original home land or relocates to new areas where they migrated during the flight process. ${ }^{6}$ It is possible that the return/resettling would be voluntary or imposed. ${ }^{7}$ Security, livelihood, past conflict effects, and service availability all play a role in the return migration process, according to studies conducted among conflict-affected populations. ${ }^{8}$
Returning returnees to their original home land after a period of displacement may be a complex and traumatizing experience. Those traumatic events that occurred during the relocation phase of the flight phase may be replayed in the minds of IDP returnees when they return to the areas of origin, raising the risk of re-traumatization. ${ }^{1}$ Conditions faced during displacement can have a detrimental impact on returning IDPs' mental wellbeing and raise their risk of chronic health problems. ${ }^{2}$

Protective factors, on the other hand, include a supportive atmosphere in which afflicted communities can obtain basic necessities, sustain or develop new social connections and relationships, and be encouraged to pursue educational and economic opportunities. ${ }^{16}$ A study from Sri Lanka found a connection between mental health and factors like female gender, unemployment, and food insecurity. ${ }^{17,18}$

According to a report, there is a negative link between the amount of time spent in exile and the mental health of returnees when they return home. Many who returned to their homes faced more mental health problems than those who were resettled in the displaced area. Returnees have had higher levels of mental illness, sexism, and vulnerability in daily life. ${ }^{10}$ IDPs can face difficulties and daily stressors when they return to their original areas. This could put them at a higher risk of developing mental illnesses. It is still unclear what factors facilitate change and rehabilitation, as well as what protective factors are linked to better mental health outcomes, according to a monk who returned to IDP. ${ }^{2}$

For returning IDPs to post-conflict areas, mental health and wellbeing issues are just as critical as developmentrelated issues such as food, protection, property, infrastructure, and sustainable living. ${ }^{18}$ There is a paucity of studies on the effect of return migration on IDP mental health. There was a massive internal displacement and returnees in Ethiopia during this study time. Despite this, no research on the mental health of Ethiopian returnees has been conducted. As a result, the aim of this study was to fill the gap by determining the prevalence and determinants of mental distress among returnees from IDPs in Ethiopia.

\section{Methods}

\section{Study Design and Setting}

From January 1 to 30, 2021, a community-based crosssectional analysis was performed. The research was carried out in Ethiopia's West-Guji (Oromia region) and Gedeo zone (SNN region). The zones are located 361 kilometres south of Addis Ababa. 


\section{Sample Size Determination and Sampling Procedure}

The following assumption was used to assess the sample size:

$n=Z_{\frac{\alpha}{2}}^{2} \times \frac{p(1-p)}{d^{2}}$

$n=1.96^{2} \times \frac{0.38(1-0.38)}{0.04^{2}} n=566$

With a $10 \%$ non-response rate, we get a total sample size of 623

$\mathrm{n}=$ Minimum sample size required for the study

$Z=$ Standard normal distribution $(Z=1.96)$ with confidence interval of $95 \%$ and $\alpha=0.05$

$P=$ Proportion of mental distress $38 \%$ was taken from a study which is done in Ethiopia, Somalia. ${ }^{19}$

$d=$ Absolute precision or tolerable margin of error $(\mathrm{d})$ $=4 \%=0.04$

The following formula was used to measure the interval size $(\mathrm{k}):-\mathrm{k}=\mathrm{N} / \mathrm{n}$

$\mathrm{K}_{1}=900 / 128=7, \mathrm{k}_{2}=1500 / 214=7, \mathrm{k}_{3}=300 / 44=7, \mathrm{k}_{4}$ $=500 / 73=7, \mathrm{k}_{5}=1200 / 164=7$

$\mathrm{K}=7$

For each kebele site the interval "k" was 7. So that, every seven person was selected from the study population

Therefore, Where- returnee population of selected kebeles

- Sample size of each kebele (proportionally allocated)

The study participants were chosen using a systematic random sampling technique. Since IDP returnees were distributed across five sites in the conflict affected district, proportional allocation to the number of returnees in each site was used to ensure sample representativeness. The interviewers visited to the region at a later time during the data collection period if an eligible person could not be presented in the visit.

\section{Study Population}

The research included all returnees aged 15 and up who were living in the West Guji and Gedeo zone during the data collection era. The research did not include people who were critically ill.

\section{Data Collection and Tools}

Five Bsc nurses collected the data, which was monitored by two mental health practitioners on a regular basis. The questionnaires were translated to Amharic language and back to English by experts to check the accuracy of the questionnaires. The interviewers were held face-to-face interviews by reading the items aloud to respondents to answer the questions.

\section{Dependent Variable}

The Kessler Psychological Distress Scale (K10) was used to assess mental distress, with a total score, $<20$ was normal, 20-24 mild distress, 25-29 moderate distress, and 30-50 extreme distress, with five potential responses ranging from "none of the time" (score 1) to "all of the time" (score 5). The scores will be dichotomized in this analysis into those who scored 20 (no mental distress), those who scored 20 (mental distress) and developed by Kessler et al. ${ }^{20}$ The current study had an internal consistency of 0.93 , a sensitivity of $84.2 \%$, and a specificity of $77.8 \%$.

\section{Independent Variables}

Stressful life event checklist (LEC-5):- 16 item stressful life events checklist was used. Those who scored one or more out of 16 stressful life events were considered as positive for stressful life events. Developed by Weathers et al. ${ }^{21}$ An internal consistency of 0.89 , a sensitivity of $81 \%$ and a specificity of $79.2 \%$ were reported in the current study.

The Oslo-3 scale with 3-item questionnaires used to measure social support. It uses a sum score scale of 3-14, with three categories: weak support (3-8), moderate support (9-11), and good support (12-14) and developed by Abiola. $^{22}$ The current study had an internal consistency of 0.94 , a sensitivity of $91.2 \%$, and a specificity of $87.8 \%$.

Trauma-related factors include a list of 11 items questionnaire used to identify traumatic events experienced by returnees related to conflict, and measured by yes/no questions. Cronbach's $\alpha=0.85$.

Displacement-related factors include duration of displacement, frequency of displacement, hatred between ethnic groups, health status at the time of return, knowledge of life after return measured and operationalized based on different literatures. Cronbach's $\alpha=0.81$.

Clinical factors include ever being treated for mental illness, and family history of mental illness, which was measured by using yes/no responses. Sociodemographic variables like sex, age, marital status, religion, ethnicity, educational status, occupation and current living condition were used to assess the background of participants and operationalized based on different literatures.

\section{Statistical Analysis}

Data was checked, coded, and entered using Epi data version 4.2, and then exported to SPSS V.24 for descriptive methods 
analysis and table summarization. Using logistic regression analyses, associations between mental distress and related factors were discovered. Multivariable logistic regression models were built after each bivariable logistic regression was completed. A P-value of less than 0.05 was taken as statistically significant, and the strength of the associations was calculated using an adjusted odds ratio (AOR) with a $95 \%$ confidence interval $(\mathrm{CI})$.

\section{Ethical Approval and Consent to Participation}

Both data collection procedures were carried out in compliance with the Helsinki Declaration and the ethical review board of Dilla University, Health science and Medical College. The research was accepted by Dilla University's Health Science and Medical College's ethical review board. The participants were told about the study's purpose, and no personal information or names were registered in order to preserve confidentiality.

Participants in the study were also given the option to reject or withdraw their participation at any time during the interview. Finally, the written informed consent for participants with age 18 years and above, and assent (parental informed consent) was obtained for under age 18 years before data were collected. Participants who tested positive for emotional distress during the study were referred to a local psychiatric facility for further evaluation of their condition.

\section{Results}

\section{Socio-Demographic Characteristics of} the Respondents

The study included a total of 623 participants, with a $100 \%$ response rate. The respondents' average age (SD) was 32.3 (10.22), with ages varying from 15 to 79 . $238(38.2 \%)$ of the respondents were between the ages of 25 and 34, 346 (55.5\%) were male, 403 (64.7\%) were married, and 224 (35.9\%) had attended primary school. Around 208 people (33.49\%) worked as farmers, while $226(36.3 \%)$ were Gedeo by ethnicity (Table 1$)$.

\section{Psychosocial, Clinical, and Displacement-Related Factors of Respondents}

More than half of the participants with mental illness (496) were afraid of security and safety issues, 308 (49.4\%) complained of ethnic hate, $336(53.9 \%)$ complained of inadequate
Table I Distribution of Socio-Demographic Factors Among Returnees in Ethiopia, $2021 \quad(n=623)$

\begin{tabular}{|c|c|c|}
\hline Variable & Frequency & Percentage (\%) \\
\hline \multicolumn{3}{|l|}{ Age } \\
\hline $15-24$ & 106 & I7.1 \\
\hline $25-34$ & 238 & 38.2 \\
\hline $35-44$ & 131 & 21.1 \\
\hline $45-54$ & 75 & 12.1 \\
\hline $55-64$ & 43 & 6.9 \\
\hline$\geq 65$ & 30 & 4.8 \\
\hline \multicolumn{3}{|l|}{ Sex } \\
\hline Male & 346 & 55.5 \\
\hline Female & 277 & 44.5 \\
\hline \multicolumn{3}{|l|}{ Religion } \\
\hline Muslim & 96 & 15.4 \\
\hline Orthodox & 162 & 26.1 \\
\hline Protestant & 365 & 58.6 \\
\hline \multicolumn{3}{|l|}{ Marital status } \\
\hline Widower & 41 & 6.5 \\
\hline Married & 403 & 64.7 \\
\hline Divorced & 55 & 8.8 \\
\hline Single & 124 & 19.9 \\
\hline \multicolumn{3}{|l|}{ Ethnicity } \\
\hline Oromo & $15 \mid$ & 22.8 \\
\hline Gedeo & 226 & 36.3 \\
\hline Amhara & 138 & 22.2 \\
\hline Gurage & 60 & 9.6 \\
\hline Others* & 48 & 7.7 \\
\hline \multicolumn{3}{|l|}{ Educational status } \\
\hline Not read \& write & 142 & 22.8 \\
\hline Primary & 224 & 35.9 \\
\hline Secondary & 197 & 31.6 \\
\hline College above & 60 & 9.6 \\
\hline \multicolumn{3}{|l|}{ Occupation } \\
\hline Farmer & 208 & 33.4 \\
\hline Merchant & 143 & 22.9 \\
\hline Employee & 98 & 15.7 \\
\hline Unemployed & 61 & 9.8 \\
\hline Student & 67 & 10.7 \\
\hline Daily labourer & 46 & 7.4 \\
\hline \multicolumn{3}{|l|}{ Current living condition } \\
\hline Poor & 456 & 73.2 \\
\hline Good & 167 & 26.8 \\
\hline
\end{tabular}

Note: Others*= Sidama, Amaro, wolaita.

social care, and 353 (56.7\%) had little knowledge of lifestyle after return. In terms of clinical characteristics, 168 (26.9\%) of the respondents were in poor health at the time of return. 261 (41.9\%) of the total study participants were displaced several times (see Table 2). 
Table 2 Descriptions of Psychosocial, Clinical and DisplacementRelated Factors of Respondents Among Returnees in Ethiopia, 2021 $(n=623)$

\begin{tabular}{|c|c|c|}
\hline Variables & Frequency & Percentage (\%) \\
\hline \multicolumn{3}{|l|}{ Had security and safety } \\
\hline Yes & 496 & 79.6 \\
\hline No & 127 & 20.4 \\
\hline \multicolumn{3}{|l|}{ Fear of rejection } \\
\hline Yes & 343 & 55.1 \\
\hline No & 280 & 44.9 \\
\hline \multicolumn{3}{|l|}{ Hatred between ethnic groups } \\
\hline Yes & 308 & 49.4 \\
\hline No & 317 & 50.6 \\
\hline \multicolumn{3}{|l|}{ Ever treated for mental illness } \\
\hline Yes & 123 & 19.7 \\
\hline No & 500 & 80.3 \\
\hline \multicolumn{3}{|l|}{$\begin{array}{l}\text { Family member treated for } \\
\text { mental illness }\end{array}$} \\
\hline Yes & 36 & 5.8 \\
\hline No & 587 & 94.2 \\
\hline \multicolumn{3}{|l|}{ Stressful life event } \\
\hline Yes & 331 & 53.1 \\
\hline No & 292 & 46.9 \\
\hline \multicolumn{3}{|l|}{ Health status at the time of return } \\
\hline Poor & 168 & 26.9 \\
\hline Same as before & 405 & 65 \\
\hline Good & 101 & 16.1 \\
\hline \multicolumn{3}{|l|}{ Knowledge of life style after return } \\
\hline Know much & 69 & 11.1 \\
\hline Know some & 201 & 32.3 \\
\hline Did not know at all & 353 & 56.7 \\
\hline \multicolumn{3}{|l|}{ Duration since displacement } \\
\hline $9-12$ month & 145 & 23.3 \\
\hline$>12$ month & 478 & 76.7 \\
\hline \multicolumn{3}{|l|}{ Frequency of displacement } \\
\hline I time & 362 & 58.1 \\
\hline$>$ I time & 261 & 41.9 \\
\hline \multicolumn{3}{|l|}{ Social support } \\
\hline Poor & 336 & 53.9 \\
\hline Moderate & 184 & 29.5 \\
\hline Strong & 103 & 16.5 \\
\hline
\end{tabular}

\section{Trauma Related Factors}

The most common form of trauma faced by returnees was inadequate housing/shelter, which accounted for 385 $(61.8 \%)$ of the total study participants, followed by forced separation from family, which accounted for 370 (59.4\%).
A third of the participants, 192 (30.8\%), had witnessed a family murder. In terms of the number of traumatic events, 117 people (18.9\%) had experienced $1-3$ and 478 people (76.7\%) had experienced $\geq 3$ of the 12 traumatic events covered by the questionnaire. Male participants recorded the highest number of stressful events (369 or 59.2\%), compared to female participants (261 or 40.7\%) (See Table 3).

\section{Prevalence of Mental Distress Among Returnees}

In this study, the prevalence of mental distress was $49.4 \%$ with a $95 \%$ CI of (47-52.9\%). The estimated prevalence rate was higher among females (70.7\%) compared to males (42.2\%).

\section{Independent Variables Associated with Mental Distress}

In multivariable logistic regression, variables with a P-value of less than 0.2 in bivariate regression were included. At a p-value of 0.05, unemployment, a lack of social care, a lack of awareness of post-returnee life, and the amount of traumatic incidents were statistically significant with PTSD in a multivariate logistic regression.

Table 3 Description of Traumatic Experiences of Respondents Among Returnees in Ethiopia, 2021 ( $n=623)$

\begin{tabular}{|c|c|c|c|c|}
\hline $\begin{array}{l}\text { Traumatic Event } \\
\text { Experienced by } \\
\text { Returnee }\end{array}$ & \multicolumn{3}{|c|}{ Frequency } & $\begin{array}{l}\text { Percentage } \\
\text { (\%) }\end{array}$ \\
\hline Poor housing or shelter & \multicolumn{3}{|l|}{385} & 61.8 \\
\hline Lack of food or water & \multicolumn{3}{|l|}{220} & 35.3 \\
\hline Rape or sexual abuse & \multicolumn{3}{|l|}{196} & 31.5 \\
\hline Lack of health care access & \multicolumn{3}{|l|}{218} & 34.9 \\
\hline Tortured or beaten & \multicolumn{3}{|l|}{206} & 33.1 \\
\hline Serious injury & \multicolumn{3}{|l|}{242} & 38.8 \\
\hline $\begin{array}{l}\text { Witnessing murder of } \\
\text { stranger }\end{array}$ & \multicolumn{3}{|l|}{192} & 30.8 \\
\hline Forced separation & \multicolumn{3}{|l|}{370} & 59.4 \\
\hline Lose of family or friends & \multicolumn{3}{|l|}{150} & 24.1 \\
\hline $\begin{array}{l}\text { Being abducted or } \\
\text { kidnapped }\end{array}$ & \multicolumn{3}{|l|}{198} & 31.8 \\
\hline Physical abuse & \multicolumn{3}{|l|}{$|4|$} & 22.6 \\
\hline $\begin{array}{l}\text { Number of traumatic } \\
\text { events }\end{array}$ & Male & Female & Total & \\
\hline 0 trauma events & 13 & 15 & 28 & 4.5 \\
\hline I-2 trauma events & 61 & 56 & 117 & 18.9 \\
\hline$\geq 3$ trauma events & 295 & 183 & 478 & 76.7 \\
\hline Total & 369 & 254 & 623 & 100 \\
\hline
\end{tabular}


Unemployed people were twice as likely as their counterparts to experience mental distress ( $\mathrm{AOR}=2,95 \% \mathrm{CI}$ $1.38,3.40)$. Participants with little experience of postreturnee life were 2.2 times more likely than their counterparts to develop mental illness (AOR $=2.2,95 \%$ CI 1.23 to 3.37$)$.

The odds of experiencing mental distress were 1.92 times higher among people with inadequate social support compared to those with adequate social support $(\mathrm{AOR}=1.92$, $95 \%$ CI 1.53, 2.56). Participants who had experienced $1-2$ traumatic events were 1.5 times more likely to have mental distress (AOR $=1.52,95 \%$ CI 1.23, 2.79) and those who had experienced $\geq 3$ traumatic events were 3.62 times more likely to have mental distress ( $\mathrm{AOR}=3.62,95 \% \mathrm{CI} 1.82,4.03)$ than those who had not experienced any of the 12 trauma events in this sample (Table 4).

Table 4 The Association of Predictors and Mental Distress Among Returnees in Ethiopia, 202I ( $n=623)$

\begin{tabular}{|c|c|c|c|c|}
\hline \multirow[t]{2}{*}{ Variables } & \multicolumn{2}{|c|}{ Mental Distress } & \multirow[t]{2}{*}{ COR(95\% Cl) } & \multirow[t]{2}{*}{ AOR(95\% Cl) } \\
\hline & Yes & No & & \\
\hline \multicolumn{5}{|l|}{ Sex } \\
\hline Female & 196 & 81 & $3.31(1.84,5.37)$ & $2.9(0.61,3.44)$ \\
\hline Male & 146 & 200 & 1 & 1 \\
\hline \multicolumn{5}{|l|}{ Occupation } \\
\hline Farmer & 157 & 27 & $1.08(0.18,1.55)$ & $1.40(0.61,3.17)$ \\
\hline Merchant & 143 & 25 & $0.99(0.85,2.53)$ & I.08(0.5I, 2.29) \\
\hline Unemployed & 112 & II & $1.76(1.57,2.24)$ & $2.05(1.38,3.40)^{* *}$ \\
\hline Student & 67 & 12 & $0.97(0.22,1.47)$ & $0.6 I(0.24,1.53)$ \\
\hline Daily labourer & 46 & 8.0 & $1.03(0.52,1.99)$ & $\mathrm{I} .82(0.70,4.71)$ \\
\hline Employee & 98 & 29 & 1 & I \\
\hline \multicolumn{5}{|l|}{ Poor housing/shelter } \\
\hline Yes & 196 & 89 & $4.5(0.95,7.25)$ & $2.26(0.76,3.08)$ \\
\hline No & 78 & 160 & I & I \\
\hline \multicolumn{5}{|c|}{ Duration since displacement } \\
\hline$>12$ month & 278 & 200 & $0.95(0.97,1.89)$ & $2.69(0.35,5.82)$ \\
\hline $6-12$ month & 86 & 59 & 1 & I \\
\hline \multicolumn{5}{|c|}{ Health status at the time of return } \\
\hline Poor & 115 & 50 & $5.7(2.26,8.37)$ & $3.5(0.98,5.44)$ \\
\hline Same as before & 128 & 277 & $1.15(0.95,1.56)$ & $1.78(0.56,2.03)$ \\
\hline Good & 29 & 72 & I & I \\
\hline \multicolumn{5}{|c|}{ Knowledge of life style after return } \\
\hline Know much & 30 & 39 & I & I \\
\hline Know some & 78 & 123 & $0.82(0.32,1.52)$ & $0.69(0.41,1.63)$ \\
\hline Did not know at all & 143 & 110 & $1.69(1.41,2.63)$ & $2.17(1.23,3.37)^{* *}$ \\
\hline \multicolumn{5}{|l|}{ Social support } \\
\hline Poor & 238 & 98 & $1.43(1.18,2.14)$ & $1.92(1.53,2.56)^{* * *}$ \\
\hline Moderate & 90 & 94 & $0.56(0.86,1.21)$ & $1.31(0.56,3.04)$ \\
\hline Good & 68 & 40 & 1 & 1 \\
\hline \multicolumn{5}{|l|}{ Had security and safety } \\
\hline Yes & 296 & 200 & $2.28(1.54,2.8 I)$ & $2.4(0.94,4.08)$ \\
\hline No & 50 & 77 & I & 1 \\
\hline \multicolumn{5}{|c|}{ Number of traumatic events } \\
\hline 0 traumatic event & 8 & 20 & I & I \\
\hline I-2 traumatic events & 60 & 57 & $2.63(1.20,2.18)$ & $1.52(1.23,1.79)^{* *}$ \\
\hline$\geq 3$ traumatic events & 298 & 180 & $4.14(1.56,3.65)$ & $3.62(1.82,4.03)^{* * *}$ \\
\hline
\end{tabular}

Notes: $* * 0.05, * * *<<0.001$. Chi-square $=5$, degree of freedom $=8$, Hosmer-lemeshow test $=0.82$. 


\section{Discussion}

The prevalence of mental distress and its predictors among IDP returnees in Ethiopia were investigated in this report. The prevalence of mental illness among returnees was $49.4 \%$ (95\% CI 47 to 52.9 ), according to this report. This research matched that of a study conducted in Kosovo. ${ }^{13}$ The prevalence rate was higher among females (70.7\%) compared to males (42.2\%). Even though women had experienced a lower number of traumatic events than men, greater prevalence of mental distress was reported. This could be that women have a lower threshold from exposure to psycho-trauma like sexual abuse, which may have a more severe effect on women to have more prevalence compared to males. ${ }^{23}$ Females tend to bear the burden of family, and care responsibilities in the context of Ethiopia could be another reason to report greater prevalence. ${ }^{24}$

On the other hand, the current study's findings were lower than those of a study of German IDP returnees. ${ }^{10}$ The disparity may be due to exposure to various forms of trauma, as well as differences in study area and sampling technique. Another factor contributing to the disparity is the use of different instruments; mental wellbeing was measured using the standardized interview M.I.N.I in German, ${ }^{10,21}$ and in this study, the Kessler psychological distress scale (k-10) was used. ${ }^{20}$ This may also be due to differences in sample size, study environment, and the lack of necessary resource support. ${ }^{10}$

In contrast, the current study's estimated prevalence was higher than studies conducted in Ethiopia among returnees from the Middle East and South Africa. ${ }^{11,12}$ The difference in method could explain the observed differences, as South African and Middle East returnees were evaluated using the self-reporting questionnaire (SRQ-20). ${ }^{12}$ An interviewer-administered questionnaire based on the Self Report Questionnaire-20 $0^{11}$ was used in the Middle East returnee study, and the Trauma Screening Questionnaire was used in Georgia, ${ }^{25}$ but the current study used the Kessler psychological distress scale (k-10). Internal displacement was the reason for this study's returnees, whereas other studies listed in Ethiopian were conducted among returnees from other countries. ${ }^{11,12}$ Another explanation may be the length of displacement, as most studies were performed after several years of displacement, ${ }^{11,12,25}$ while the current research was conducted after just two years of return to home land. As a result, longer durations were more likely to minimize the severity of mental distress caused by recall bias. Another explanation may be differences in the type of trauma exposure, sampling methodology, and socio-cultural factors. ${ }^{14,15,25}$

Unemployment, inadequate social support, the amount of traumatic incidents, having little awareness of life after return, and poor living conditions were all significantly associated with mental distress in IDP returnees, according to multivariate logistic regression.

And as opposed to their counterparts, those who were unemployed were twice as likely to experience mental distress. The explanation for this may be that after being laid off, the symptoms of somatization, depression, and anxiety were substantially higher in the unemployed, and they had a lower degree of mental and life satisfaction than their counterparts. ${ }^{26,27}$ Unemployment has personal and social costs, such as severe financial distress, hunger, homelessness, housing stress, and family breakdown, which has an impact on returnees' mental health. ${ }^{15,17,28}$

Another factor closely correlated with emotional distress was the number of traumatic events; participants who experienced 1-2 and $\geq 3$ traumatic events during relocation were 1.5 times and 3.62 times more likely to have emotional distress, respectively, than those who did not. This may be because participants who have been exposed to trauma once, several times, or over a long period of time have a more negative impact on returnees' mental health. ${ }^{29,30}$

Participants who received inadequate social support were 1.92 times more likely than their counterparts to experience emotional distress. This may be because inadequate social support has been related to depression, loneliness, and has been shown to change brain function and raise the likelihood of alcohol consumption, depression, and suicide. ${ }^{1,31-33}$ Research has also shown that having a good social support system in place during a crisis will help to mitigate the effects of trauma-related mental health issues. $^{17,34}$

Furthermore, those with little awareness of postreturnee life were 2.2 times more likely than their counterparts to experience mental distress. The explanation for this may be that returnees' mental health is influenced by their lack of experience and information about the prospects of post-returnee lives and circumstances. Returnees who become more stressed as a result of the difficulties of adjusting to post-returnee life and re-establishing their original social network, as well as economic losses and lost assets. ${ }^{12,34}$ 


\section{Strength and Limitation of the Study}

Inside of strength, this study included the most important variables that were not included in most of the studies. Second, both dependent and independent variables were measured using standardized and validated tools. Although including participants or returnee IDPs from a single location (zone) and excluding returnees who have been resettled in host communities may be considered some of the limitations of the study.

\section{Conclusion}

The prevalence of psychological distress among returnee IDPs was found to be high in this study. To cope with psychological distress and related factors including unemployment, minimal education, inadequate social support, and a high number of traumatic events, providing psycho education of how to adjust to a new life after returning to the original land and providing consistent psychosocial support should be recommended. I recommend that government and non-government organizations who are currently working with IDP returnees need to screen mental health and provide appropriate intervention to mitigate the long-term mental health effects of traumatic events.

\section{Abbreviations}

IDP, Internally Displaced People; IDMC, Internal Displaced Monitoring Center; K-10, Kessler psychological distress scale; PTSD, Post-Traumatic Stress Disorder.

\section{Data Sharing Statement}

Upon fair request, the corresponding author will provide the datasets used and analysed during the current analysis.

\section{Acknowledgments}

For their support, the author of this study would like to thank the entire staff of the Gedeo and Guji zone administrators, as well as local leaders. My heartfelt thanks to Dilla University's college of health science and medicine's department of psychiatry for their invaluable assistance. I also thanked the study participants for their help in gathering the required data.

\section{Funding}

The research received no particular grant from any funding agency in the public, commercial or not-for-profit sectors.

\section{Disclosure}

The author reports no conflicts of interest in this work.

\section{References}

1. Mels C, Derluyn I, Broekaert E, Rosseel Y. The psychological impact of forced displacement and related risk factors on Eastern Congolese adolescents affected by war. J Child Psychol Psychiatry. 2010;51 (10):1096-1104. doi:10.1111/j.1469-7610.2010.02241.x

2. Siriwardhana C, Stewart R. Forced migration and mental health: prolonged internal displacement, return migration and resilience. Int Health. 2013;5(1):19-23. doi:10.1093/inthealth/ihs014

3. Hochrainer-Stigler S, Mechler R, Cazabat C, editors. Points of No Return-Estimating Governments Fiscal Resilience to Internal Displacement. IDMC; 2019.

4. Murthy RS, Lakshminarayana R. Mental health consequences of war: a brief review of research findings. World Psychiatry. 2006;5(1):25.

5. Betts A, Bloom L. Humanitarian Innovation: The State of the Art: United Nations Office for the Coordination of Humanitarian Affairs. OCHA; 2014.

6. Mooney E. The concept of internal displacement and the case for internally displaced persons as a category of concern. Refugee Survey Quart. 2005;24(3):9-26. doi:10.1093/rsq/hdi049

7. Bozzoli C, Brück T, Muhumuza T. Movers or Stayers? Understanding the Drivers of IDP Camp Decongestion During PostConflict Recovery in Uganda. 2012.

8. Thomas SL, Thomas SD. Displacement and health. Br Med Bull. 2004;69(1):115-127. doi:10.1093/bmb/ldh009

9. Roth G, Ekblad S, Ågren H. A longitudinal study of PTSD in a sample of adult mass-evacuated Kosovars, some of whom returned to their home country. Eur Psychiatry. 2006;21(3):152-159. doi:10.1016/j.eurpsy.2005.11.004

10. Von Lersner U, Wiens U, Elbert T, Neuner F. Mental health of returnees: refugees in Germany prior to their state-sponsored repatriation. BMC Int Health Hum Rights. 2008;8(1):1-13. doi:10.1186/1472-698X-8-8

11. Zeleke W, Minaye A, Kygana G. Mental health and somatic distress among Ethiopian migrant returnees from the Middle East. Int J Ment Health Psychiatry. 2015;1:2. doi:10.4172/2471-4372.1000106

12. Habtamu K, Minaye A, Zeleke WA. Prevalence and associated factors of common mental disorders among Ethiopian migrant returnees from the Middle East and South Africa. BMC Psychiatry. 2017;17 (1):1-11. doi:10.1186/s12888-017-1310-6

13. Toscani L, DeRoo LA, Eytan A, et al. Health status of returnees to Kosovo: do living conditions during asylum make a difference? Public Health. 2007;121(1):34-44. doi:10.1016/j.puhe.2006.06.017

14. Tilahun M, Workicho A, Angaw DA. Common mental disorders and its associated factors and mental health care services for Ethiopian labour migrants returned from Middle East countries in Addis Ababa, Ethiopia. BMC Health Serv Res. 2020;20(1):1-13. doi:10.1186/ s12913-020-05502-0

15. Zewdu A, Suleyiman M. Depression and coping mechanism among migrant returnees from Middle East countries in Amhara region, Ethiopia. Health Sci J. 2018;12(2):1-12. doi:10.21767/1791809X.1000560

16. Marquez PV. Mental Health Among Displaced People and Refugees: Making the Case for Action at the World Bank Group. The World Bank; 2017.

17. Siriwardhana C. Mental health of displaced and returnee populations: insight from the Sri Lankan post-conflict experience. Confl Health. 2015;9(1):1-3. doi:10.1186/s13031-015-0049-2

18. Siriwardhana C, Wickramage K. Conflict, forced displacement and health in Sri Lanka: a review of the research landscape. Confl Health. 2014;8(1):1-9. doi:10.1186/1752-1505-8-22 
19. Feyera F, Mihretie G, Bedaso A, Gedle D, Kumera G. Prevalence of depression and associated factors among Somali refugee at melkadida camp, southeast Ethiopia: a cross-sectional study. BMC Psychiatry. 2015;15(1):1-7. doi:10.1186/s12888-015-0539-1

20. Kessler RC, Andrews G, Colpe LJ, et al. Short screening scales to monitor population prevalences and trends in non-specific psychological distress. Psychol Med. 2002;32(6):959. doi:10.1017/ S0033291702006074

21. Weathers F, Blake D, Schnurr P, Kaloupek D, Marx B, Keane T. The Life Events Checklist for DSM-5 (LEC-5). PTSD; 2013. Available from: Www.Ptsd.Va.Gov. Accesed August 23, 2021.

22. Abiola T, Udofia O, Zakari M. Psychometric properties of the 3-item oslo social support scale among clinical students of Bayero University Kano, Nigeria. Malaysian J Psychiatry. 2013;22(2):32-41.

23. Almedom A, Tesfamichael B, Mohammed Z, Mascie-Taylor N, Muller J, Alemu Z. Prolonged displacement may compromise resilience in Eritrean mothers. Afr Health Sci. 2005;5(4):310-314.

24. Amodu OC, Richter MS, Salami BO. A scoping review of the health of conflict-induced internally displaced women in Africa Int J Environ Res Public Health. 2020;17(4):1280. doi:10.3390/ ijerph 17041280

25. Makhashvili N, Chikovani I, McKee M, Bisson J, Patel V, Roberts B. Mental disorders and their association with disability among internally displaced persons and returnees in Georgia. J Trauma Stress. 2014;27(5):509-518. doi:10.1002/jts.21949

26. Warr P. Work, Unemployment, and Mental Health. Oxford University Press; 1987.
27. Murphy GC, Athanasou JA. The effect of unemployment on mental health. J Occup Organ Psychol. 1999;72(1):83-99. doi:10.1348/ 096317999166518

28. Paul KI, Moser K. Unemployment impairs mental health: meta-analyses. J Vocat Behav. 2009;74(3):264-282. doi:10.1016/j. jvb.2009.01.001

29. O'Brien LS. Traumatic Events and Mental Health. Cambridge University Press; 1998.

30. Eisen SV, Schultz MR, Glickman ME, et al. Postdeployment resilience as a predictor of mental health in operation enduring freedom/ operation Iraqi freedom returnees. Am J Prev Med. 2014;47 (6):754-761. doi:10.1016/j.amepre.2014.07.049

31. Murakami M, Takebayashi Y, Tsubokura M. Lower psychological distress levels among returnees compared with evacuees after the Fukushima nuclear accident. Tohoku J Exp Med. 2019;247 (1):13-17. doi:10.1620/tjem.247.13

32. Kessler RC, McLeod JD. Social Support and Mental Health in Community Samples. Academic Press; 1985.

33. Riahi M, Aliverdinia A, Pourhossein Z. Relationship between social support and mental health. Soc Welfare Quart. 2011;10(39):85-121.

34. Burns R, Wickramage K, Musah A, Siriwardhana C, Checchi F. Health status of returning refugees, internally displaced persons, and the host community in a post-conflict district in northern Sri Lanka: a cross-sectional survey. Confl Health. 2018;12(1):1-12. doi:10.1186/s13031-018-0176-7
Neuropsychiatric Disease and Treatment

\section{Publish your work in this journal}

Neuropsychiatric Disease and Treatment is an international, peerreviewed journal of clinical therapeutics and pharmacology focusing on concise rapid reporting of clinical or pre-clinical studies on a range of neuropsychiatric and neurological disorders. This journal is indexed on PubMed Central, the 'PsycINFO' database and CAS, and
Dovepress

is the official journal of The International Neuropsychiatric Association (INA). The manuscript management system is completely online and includes a very quick and fair peer-review system, which is all easy to use. Visit http://www.dovepress.com/testimonials.php to read real quotes from published authors. 